\title{
BMJ Open Cross-sectional study of HPV-16 infection in a population-based subsample of Hispanic adults
}

\author{
A P Ortiz, ${ }^{1,2}$ E R Unger, ${ }^{3}$ C Muñoz, ${ }^{2}$ G Panicker, ${ }^{3}$ G Tortolero-Luna, ${ }^{1}$ \\ M Soto-Salgado, ${ }^{4}$ Y Otero, ${ }^{4}$ E Suárez, ${ }^{2}$ C M Pérez ${ }^{2}$
}

To cite: Ortiz AP, Unger ER, Muñoz C, et al. Crosssectional study of HPV-16 infection in a populationbased subsample of Hispanic adults. BMJ Open 2014;4: e004203. doi:10.1136/ bmjopen-2013-004203

- Prepublication history for this paper is available online. To view these files please visit the journal online (http://dx.doi.org/10.1136/ bmjopen-2013-004203).

Received 8 October 2013 Revised 25 November 2013 Accepted 28 November 2013

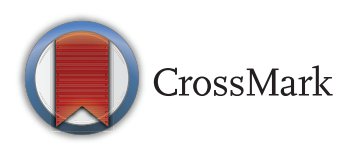

${ }^{1}$ Cancer Control and Population Sciences Program, University of Puerto Rico Comprehensive Cancer Center, San Juan, Puerto Rico

${ }^{2}$ Biostatistics and Epidemiology Department, Graduate School of Public Health, University of Puerto Rico, San Juan, Puerto Rico ${ }^{3}$ Chronic Viral Diseases Branch, Centers for Disease Control and Prevention, Atlanta, Georgia, USA ${ }^{4}$ UPR-MDACC Partnership for Excellence in Cancer Research, School of Medicine, Medical Sciences Campus, University of Puerto Rico, San Juan, Puerto Rico

Correspondence to Dr Ana Patricia Ortiz; ana.ortiz7@upr.edu

\section{ABSTRACT}

Objective: This study aimed to estimate the prevalence and correlates of seropositivity to human papillomavirus (HPV)-16 in a subsample of adults who participated in the parent study Epidemiology of Hepatitis $C$ in the adult population of Puerto Rico (PR).

Setting: The parent study was a population-based household survey aimed to estimate the seroprevalence of hepatitis $C$ and other viral infections (hepatitis $A$, hepatitis B, HIV, and herpes simplex type 2) in PR ( $n=1654$ ) between 2005 and 2008.

Participants: A subsample of the last 450 consecutive adults aged 21-64 years, recruited between February 2007 and January 2008, who participated in the parent study and agreed to participate in HPV testing.

Primary and secondary outcome measures: The samples were tested by ELISA for HPV-16 viral-like particle-specific immunoglobulin G. Information on sociodemographic, health, and lifestyle characteristics was collected. Logistic regression modelling was used to estimate the prevalence odds ratio (POR) to assess factors associated to HPV-16 seropositivity.

Results: Prevalence of seropositivity to HPV-16 was $11.3 \%$. Seroprevalence was higher in women $(15.8 \%)$ than men (5.6\%; $p=0.001)$. After adjusting for age and sex, ever smokers (POR 2.06, 95\% Cl 1.08 to 3.92) and participants with at least five lifetime sexual partners (POR 2.91, 95\% $\mathrm{Cl} 1.24$ to 6.81) were more likely to be HPV-16 seropositive.

Conclusions: HPV-16 seropositivity is similar to that reported in the USA (10.4\%) for NHANES 2003-2004 participants, although different assays were used in these studies. While future studies should evaluate HPV seroprevalence using a larger population-based sample, our results highlight the need to further understand the burden of HPV infection and HPVrelated malignancies in $\mathrm{PR}$, population with a low vaccine uptake.

\section{INTRODUCTION}

Human papillomavirus (HPV) is the most common sexually transmitted infection worldwide. Persistent infection with certain

\section{Strengths and limitations of this study}

- This study is the first to provide initial insights of the epidemiology of human papillomavirus (HPV) infection by assessing HPV-16 seroprevalence and its correlates in Puerto Rico.

- Although different laboratory assays were used, our estimate of HPV-16 seropositivity for this subsample of adults in Puerto Rico (11.3\%) from 2005 to 2008 is comparable with that reported in the USA $(10.4 \%)$ for persons aged 14-59 years participating in the NHANES 20032004.

- Study limitations include the lack of HPV vaccination data of study participants and the modestly sized sample of HPV-16 seropositive individuals, limiting the power of our study to detect significant associations with HPV serology.

types of HPV has been established as a necessary cause for cervical cancer ${ }^{1}{ }^{2}$ and has been associated with cancer of the anus, vulva, vagina, penis, and oropharynx. ${ }^{3}{ }_{4}^{4}$ Approximately $5.2 \%$ of all cancers worldwide are attributable to HPV infection. ${ }^{3}$ Moreover, the economic burden of HPV infection is high, and second only to the cost of HIV infection. ${ }^{5}$ Currently, there are two HPV vaccines licensed for use worldwide that have proven to be effective in preventing HPV infection and progressive disease in people who were previously HPV naïve. ${ }^{6}$ With widespread use, the vaccines could provide a costeffective prevention strategy.

Antibody response to HPV infection is considered a key determinant of protective immunity and may play a role as a predictor of HPV-associated cervical neoplasia. ${ }^{2} 7$ The protective antibody response is mainly typespecific and directed against conformational epitopes of the major capsid protein L1, while antibodies to E6 and E7 oncoproteins may be markers of invasive cervical cancer, with tumour stage and mass determining the magnitude of the response. ${ }^{9}$ Seroconversion 
occurs several months after detection of HPV-DNA infection; approximately only $60 \%$ of women with an incident HPV-DNA infection seroconvert within 18 months after detection. No differences in median time of seroconversion are observed by HPV type, although antibody responses to high-risk HPV types have been found to persist longer. ${ }^{1}{ }^{10}$ While HPV DNA testing detects current infection, serological testing serves as a useful epidemiological research tool to measure lifetime exposure to HPV infection because antibodies may persist even after the virus has cleared. Although HPV-16 is the most common HPV type detected in most regions of the world, ${ }^{11}$ no population-based seroepidemiological studies of HPV-16 infection have been conducted in Puerto Rico (PR). An estimate of natural HPV infection would not only help understand the burden of the disease, but also provide the necessary baseline data for HPV vaccine implementation and monitoring in PR. Hence, the purpose of this pilot study was to estimate prevalence of HPV-16 immunoglobulin $\mathrm{G}(\mathrm{IgG})$ responses and factors associated with HPV-16 seropositivity in a cross-section of adults in PR.

\section{MATERIALS AND METHODS}

Study design and population

An island-wide, population-based cross-sectional household survey aimed at estimating the seroprevalence of hepatitis $\mathrm{C}$ and other viral infections (hepatitis $\mathrm{A}$, hepatitis B, HIV, and herpes simplex type 2) was performed in PR $(n=1654)$ between 2005 and 2008. Detailed descriptions of the study sampling design and data collection procedures have been previously published. ${ }^{12}$ In brief, a cluster sampling design for household surveys using the census tracts of PR was employed, and one individual aged 21-64 years from each selected household was randomly selected to participate in the study. Participants underwent a personal interview and an audio computer-assisted self-interview (ACASI) using QDS (Nova Research Co., Washington DC, USA), and provided a sample of blood for serological testing. For the current analysis, we used residual serum from a subsample of the last 450 consecutive adults aged 21-64 years, recruited between February 2007 and January 2008, who participated in the study and agreed to participate in HPV testing.

\section{Serological testing}

Antibody testing for HPV-16 was performed at the Human Papillomavirus Laboratory at the Centers for Disease Control and Prevention in Atlanta. Virus-like particles (VLPs) were produced by expression of an HPV-16 L1 recombinant baculovirus in insect cells. ${ }^{13}$ HPV-16-specific IgG antibody was detected using a VLP-based direct ELISA as described by Karem et $a l^{13}$ but with a few modifications. Microtitre plates were coated overnight at $4^{\circ} \mathrm{C}$ with HPV-16 VLP diluted to $0.5 \mu \mathrm{g} / \mathrm{mL}$ in phosphate buffered saline. Sera (both reference and test samples) were serially diluted at $1: 10$, $1: 31.6$ and $1: 100$ in $1 \mathrm{X}$ TBST with $10 \%$ goat serum,
$10 \%$ Super-Block and 10\% insect cell lysate. An optimised concentration of goat antihuman IgG conjugated to alkaline phosphatase (EMD biosciences) diluted in 1X TBST with $10 \%$ goat serum and $10 \%$ Super-Block was used as the secondary antibody.

Sample antibody titres $(\mathrm{IU} / \mathrm{mL})$ were calculated using the parallel line method against a reference sample calibrated to the International Standard 16 (NIBSC 05/134) with known titre of $10 \mathrm{IU} / \mathrm{mL} .{ }^{14}$ A pooled serum, negative for antibodies to HPV-16, 18, 6, and 11 as tested by an alternate, competitive Luminex assay ${ }^{15}$ was used to establish cut-off value. The cut-off for positive results was set at values greater than or equal to the median antibody titre of the negative control plus two SDs $(1.97 \mathrm{IU} / \mathrm{mL})$.

\section{Study variables}

Demographic characteristics under study included age group (21-34, 35-50, 51-64 years), education $(<12$ vs $\geq 12$ years), annual family income $(<\mathrm{US} \$ 20000$ vs $\geq$ US $\$ 20000$ ), health insurance coverage (private, governmentsponsored, none) and marital status (single, married/living together, divorced/separated/widowed). Sexual practices (yes/no) included lifetime history of vaginal, anal, and oral sex as well as age of sexual initiation ( $\leq 18$ vs $>18$ years) and number of lifetime sexual partners $(0-1,2-4, \geq 5)$. In addition, we calculated the sexual exposure period by subtracting the participant's age at the first sexual intercourse from the participant's age at the time of interview. Then, the number of sexual partners was normalised to the sexual exposure period. Smoking status was assessed by a question asking participants whether they have ever smoked in their lifetime.

\section{Statistical analysis}

To characterise the demographic, clinical, and lifestyle characteristics of study participants, summary measures for continuous variables (mean $\pm \mathrm{SD}$ or median $(25$ th and 75 th centiles)) and frequency distributions for categorical variables were computed. Differences between HPV-16 seropositivity groups were assessed using Student's t-test or Mann-Whitney test for continuous variables, and $\chi^{2}$ test for independence or Fisher's exact test, when appropriate, for categorical variables. Multivariable logistic regression models were fitted to estimate the prevalence odds ratio (POR) with 95\% CIs for HPV-16 seropositivity. ${ }^{16}$ Variables statistically associated with HPV-16 seropositivity in age and sex-adjusted logistic regression models $(p<0.05)$ were included in the multivariable model. All data were evaluated using Stata for Windows release 12.0 (Stata Corporation, College Station, Texas, USA). No significant interaction terms were found in the multivariable logistic regression models evaluated $(\mathrm{p}>0.05)$.

\section{RESULTS}

Sociodemographic, clinical and lifestyle characteristics

The characteristics of the subsample of 450 adults are shown in table 1 . Three participants were HIV positive 
Table 1 Characteristics of study participants by HPV-16 serostatus $(n=450)$

\begin{tabular}{|c|c|c|c|c|}
\hline Characteristics & $\begin{array}{l}\text { Total study } \\
\text { population, } \mathrm{N}(\%)\end{array}$ & $\begin{array}{l}\text { HPV-16 negative } \\
(\mathrm{n}=399,88.7 \%) \mathrm{n}(\%)\end{array}$ & $\begin{array}{l}\text { HPV-16 positive } \\
(\mathrm{n}=51,11.3 \%) \mathrm{n}(\%)\end{array}$ & p Value \\
\hline Age group in years & & & & $0.111^{*}$ \\
\hline $21-34$ & $153(34.0)$ & $129(32.3)$ & $24(47.0)$ & \\
\hline $35-50$ & $180(40.0)$ & $164(41.1)$ & $16(31.4)$ & \\
\hline $51-64$ & $117(26.0)$ & $106(26.6)$ & $11(21.6)$ & \\
\hline Mean \pm SD & $40.9 \pm 12.3$ & $41.9 \pm 12.2$ & $38.5 \pm 12.7$ & $0.058+$ \\
\hline Sex & & & & $0.001^{*}$ \\
\hline Female & $253(56.2)$ & $213(53.4)$ & $40(78.4)$ & \\
\hline Male & $197(43.8)$ & $186(46.6)$ & $11(21.6)$ & \\
\hline Education in years & & & & $0.836^{*}$ \\
\hline$<12$ & $138(30.7)$ & $123(30.8)$ & $15(29.4)$ & \\
\hline$\geq 12$ & $312(69.3)$ & $276(69.2)$ & $36(70.6)$ & \\
\hline Annual family income $(n=424)$ & & & & $0.765^{\star}$ \\
\hline$<$ US $\$ 20,000$ & $308(72.6)$ & $274(72.9)$ & $34(70.8)$ & \\
\hline$\geq$ US $\$ 20,000$ & $312(69.3)$ & $102(27.1)$ & $14(29.2)$ & \\
\hline Marital status & & & & $0.874^{*}$ \\
\hline Never married & $77(17.1)$ & $67(16.8)$ & $10(19.6)$ & \\
\hline Married/cohabitating & $258(57.3)$ & $230(57.6)$ & $28(54.9)$ & \\
\hline Divorced/separated/widowed & $115(25.6)$ & $102(25.6)$ & $13(25.5)$ & \\
\hline Healthcare coverage & & & & $0.202 \ddagger$ \\
\hline None & $38(8.4)$ & $37(9.3)$ & $1(1.9)$ & \\
\hline Government-administered & $230(51.1)$ & $201(50.4)$ & $29(56.9)$ & \\
\hline Private & $182(40.4)$ & $161(40.3)$ & $21(41.2)$ & \\
\hline Place of birth & & & & $0.408 \mp$ \\
\hline Puerto Rico & $414(92.0)$ & $365(91.5)$ & $49(96.1)$ & \\
\hline USA & $36(8.0)$ & $34(8.5)$ & $2(3.9)$ & \\
\hline Seropositive status to HSV-2 $(n=440)$ & & & & $0.603^{*}$ \\
\hline Positive & $110(25.0)$ & $96(24.6)$ & $14(28.0)$ & \\
\hline Negative & $330(75.0)$ & $294(75.4)$ & $36(72.0)$ & \\
\hline Ever had sex $(n=445)$ & & & & $0.999 \ddagger$ \\
\hline Yes & $431(96.9)$ & $382(96.7)$ & $49(98.0)$ & \\
\hline No & $14(3.1)$ & 13 (3.3) & $1(2.0)$ & \\
\hline Age at first sexual intercourse $(n=427)$ & & & & $0.467^{\star}$ \\
\hline$<18$ & $228(53.4)$ & $200(52.8)$ & $28(58.3)$ & \\
\hline$\geq 18$ & $199(46.6)$ & $179(47.2)$ & $20(41.7)$ & \\
\hline Number of lifetime sex partners $(n=442)$ & & & & $0.349^{*}$ \\
\hline $0-1$ & $100(23.6)$ & $91(24.3)$ & 9 (18.8) & \\
\hline $2-4$ & $152(35.9)$ & $137(36.5)$ & $15(31.2)$ & \\
\hline$\geq 5$ & $171(40.4)$ & $147(39.2)$ & $24(50.0)$ & \\
\hline \multicolumn{5}{|l|}{$\begin{array}{l}\text { Number of sexual partners normalised } \\
\text { to the sexual exposure period }\end{array}$} \\
\hline Median (25th and 75th centiles) & $0.18(0.08,0.45)$ & $0.18(0.08,0.40)$ & $0.20(0.09,0.75)$ & $0.112 \dagger$ \\
\hline Anal sex & & & & $0.610^{*}$ \\
\hline Ever & $262(58.2)$ & $234(58.7)$ & $28(54.9)$ & \\
\hline Never & $188(41.8)$ & $165(41.3)$ & $23(45.1)$ & \\
\hline Oral sex & & & & $0.930^{\star}$ \\
\hline Ever & $333(74.0)$ & 295 (73.9) & $38(74.5)$ & \\
\hline Never & $117(26.0)$ & $104(26.1)$ & $13(25.5)$ & \\
\hline History of smoking & & & & $0.110^{*}$ \\
\hline Yes & $253(56.2)$ & 219 (54.9) & $34(66.7)$ & \\
\hline No & $197(43.8)$ & $180(45.1)$ & 17 (33.3) & \\
\hline
\end{tabular}

(0.66\%; data not shown). Although a comparison between the study subsample and the parent study population showed no significant differences in the clinical and lifestyle characteristics studied, a higher proportion of participants of the subsample reported less than 12 years of education $(30.7 \%$ vs $23.2 \%)$, a government- 


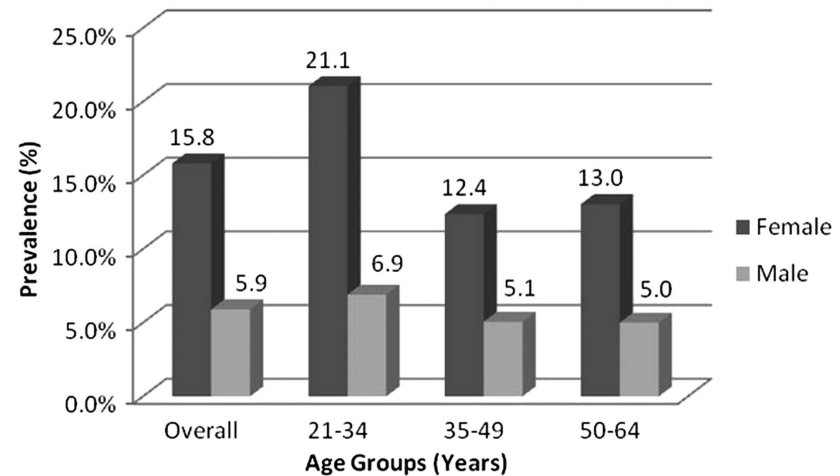

Figure 1 Seroprevalence of human papillomavirus-16 by age and sex $(n=450)$.

based health insurance (51.1\% vs $41.9 \%)$ and an annual family income below US\$20000 (72.6\% vs $63.8 \%$; $\mathrm{p}<0.05$; data not shown).

\section{Seroprevalence of HPV-16}

Overall, $11.3 \%$ of participants were seropositive to HPV-16. Seroprevalence among women $(15.8 \%)$ was higher as compared with men $(5.9 \%$; $\mathrm{p}=0.001$; figure 1 table 1). Median titres $(\mathrm{IU} / \mathrm{mL})$ for the whole sample were 6.07 (25th and 75th centiles: 2.78, 13.8); these titres were significantly higher in HPV-positive women (median: 8.39, 25th and 75th centiles: 2.68, 16.01) than in HPV-positive men (median: 3.32, 25th and 75th centiles: $3.04,7.13 ; \mathrm{p}<0.0001)$. Although no significant differences $(p>0.05)$ in prevalence were observed across age groups in men or women, the seroprevalence was higher in younger women (figure 1). The mean age of HPV-16 seropositive individuals was lower $(38.5 \pm 12.7)$ than among those HPV seronegative $(41.9 \pm 12.2)$; this result was marginally significant $(p=0.06)$. In bivariate analysis, no significant differences in seropositivity were observed by education level, household income, marital status, healthcare coverage, place of birth, sexual practices, and smoking status ( $\mathrm{p}>0.05$; table 1$)$. After adjusting for age and sex, ever smokers (POR 2.06, 95\% CI 1.08 to 3.92 ) and those reporting at least five lifetime sexual partners (POR 2.78, 95\% CI 1.15 to 6.73 ) were more likely to be HPV-16 seropositive (table 2). Nonetheless, these associations attenuated to nonsignificance in the multivariable model. Only sex remained significantly associated with HPV-16 seropositivity in multivariable analysis, with women being more likely to be seropositive as compared with men (POR $4.16,95 \%$ CI 1.91 to 9.03 ; table 2).

\section{DISCUSSION}

The first HPV vaccine, which includes HPV-16, was approved by the Food and Drug Administration (FDA) for use in the USA and PR in 2006 for women only (aged 9-26 years) and later in 2008 for men. Our estimate of HPV-16 seropositivity for this subsample of adults in PR (11.3\%) from 2005 to 2008 is comparable to those reported in the USA $(10.4 \%)$ for persons aged 1459 years participating in the NHANES 2003-2004. ${ }^{17}$ Our findings are also comparable to those reported in studies worldwide. A study in the Netherlands during 2006-2007 among persons aged $\geq 14$ years found an HPV-16 seroprevalence of $11.3 \%,{ }^{11}$ whereas a study in England among persons aged 10-49 years reported a seroprevalence of $14.7 \% .^{18}$ Also, consistent with the study by Dunne et al, ${ }^{19}$ the prevalence of HPV seroreactivity in our study was higher among women $(15.8 \%)$ than men

Table 2 Magnitude of the association (POR) between HPV-16 and different study characteristics

\begin{tabular}{|c|c|c|c|}
\hline Characteristics & Crude POR & $\begin{array}{l}\text { Age and } \\
\text { sex-adjusted POR } \\
(95 \% \mathrm{Cl})\end{array}$ & $\begin{array}{l}\text { Multivariable-adjusted } \\
\text { POR* }^{\star}(95 \% \mathrm{Cl})\end{array}$ \\
\hline \multicolumn{4}{|c|}{ Age group in years } \\
\hline $51-64$ & 1.00 & - & 1.00 \\
\hline $35-50$ & 0.96 (0.43 to 2.12$)$ & - & 0.99 (0.42 to 2.32$)$ \\
\hline 21-34 & 1.81 (0.87 to 3.79$)$ & - & 1.52 (0.67 to 3.47$)$ \\
\hline \multicolumn{4}{|l|}{ Sex } \\
\hline Male & 1.00 & - & 1.00 \\
\hline Female & 3.18 (1.58 to 6.37 ) & - & 4.16 (1.91 to 9.03$)$ \\
\hline \multicolumn{4}{|c|}{$\begin{array}{l}\text { Number of lifetime sex } \\
\text { partners }\end{array}$} \\
\hline $0-1$ & 1.00 & 1.00 & 1.00 \\
\hline $2-4$ & $1.11(0.46$ to 2.64$)$ & $1.18(0.48$ to 2.87$)$ & 1.09 (0.44 to 2.68$)$ \\
\hline$\geq 5$ & $1.65(0.73$ to 3.71$)$ & 2.78 (1.15 to 6.73$)$ & 2.36 (0.94 to 5.90$)$ \\
\hline \multicolumn{4}{|c|}{ History of smoking } \\
\hline No & 1.00 & 1.00 & 1.00 \\
\hline Yes & 1.64 (0.89 to 3.04$)$ & 2.06 (1.08 to 3.92$)$ & $1.58(0.79$ to 3.16$)$ \\
\hline
\end{tabular}

*Additionally adjusted by number of lifetime sexual partners and history of smoking; no significant interaction terms were detected in this logistic regression model $(p=0.740)$.

HPV, human papillomavirus; POR, prevalence OR. 
(5.6\%), with fourfold increased odds of infection. In a study performed by Stone $e t a l,{ }^{7} \mathrm{HPV}-16$ seroreactivity was over two times higher in women $(17.9 \%)$ than in men $(7.9 \%)$, and constant across all age and racial/ethnic groups evaluated in the study. Moreover, several studies have shown this sex difference in antibody response in all HPV vaccine types $\left(6,11,16\right.$ and 18). ${ }^{17} 18$ Sex differences in HPV-16 seroreactivity are also observed among highrisk populations. Women attending sexually transmitted diseases clinics had higher prevalence of HPV-16 seropositivity $(30.2 \%)$ than men $(18.7 \%)$, supporting that there are biological reasons for men and women differing in serological responses. ${ }^{20}$ Potential explanations proposed by Thompson et $a l^{20}$ include that men may be: (1) not as susceptible to HPV-16 infection, (2) more able to clear the infection spontaneously without developing a systemic antibody response and (3) less likely to get infected with HPV-16 given that their sexual exposure frequently involves keratinised epithelium (penis) rather than mucosal epithelium (cervix).

In concordance with the literature, HPV-16 seropositivity was also associated with lifetime number of sexual partners, a strong predictor of HPV seropositivity for men and women. $^{2} 71021$ In a study performed in Costa Rica, it was found that women with at least three lifetime sexual partners had a twofold increase in the detection of HPV-16 antibodies compared with women with one lifetime sexual partner. $^{22}$ Similarly, results from the HPV Infection in Men study showed that men with multiple lifetime male partners $(\geq 11$ partners) were more likely to be seropositive to HPV-16 (OR=7.74; 95\% CI 3.96 to 15.12$).{ }^{10}$ We observed a strong association between smoking and HPV-16 seropositivity, with smokers being more likely to be positive for HPV-16 antibodies in this sample. Smoking habits have been identified as a risk factor for HPV infection and seropositivity, but these findings are inconsistent. ${ }^{172324}$ Unlike previous studies showing a decline in seropositivity among those aged $50+$ years, we did not observe a significant association between age and HPV-16 seropositivity. ${ }^{41721}$ This could be due to the small numbers of seropositive persons in this study.

Study limitations include the lack of HPV vaccination data of participants and the sample size; only 51 samples were HPV positive, limiting the power of our study to detect significant associations with HPV serology. Future studies should evaluate HPV seroprevalence using a larger population-based sample; the research team is currently executing a population-based study among women living in the San Juan metropolitan area, which will soon produce data on this topic. All HPV serology assays are limited by the lack of commercial reagents and difficulties in comparing results between different platforms. We reported on results in terms of IU to help in interstudy comparisons.

This study is the first to evaluate the prevalence and correlates of HPV seroprevalence in PR. With the introduction of the two prophylactic HPV vaccines, it is important to establish baseline population HPV prevalence and better identify population subgroups at high risk for HPV-related cancers in the population before the uptake of the vaccine continues to increase. This is particularly important in PR, where populationbased estimates of vaccine uptake are low among children and adults ( $<5 \%$ among women aged 16-26 years; 2010-2013 data). ${ }^{25}$ Knowledge of the burden of infection prior to the expansion of these programmes will allow a better assessment and understanding of the short-term and long-term effectiveness of this primary prevention strategy for anogenital lesions (cervix, vagina, vulva, and anus). Thus, these initial findings provide a much needed insight on the epidemiology of HPV infection in PR and will permit the expansion of future HPV-related research.

Contributors APO, CMP and ES contributed to the concept and design; monitoring of the data collection and quality, analysis and interpretation of the data; drafting the article and revising it based on reviewer comments. GT-L contributed to the concept and design and interpretation of the data and revised the article for important intellectual content. CM, MS-S and YO contributed to the concept, data analysis and interpretation of the data; drafting the article and revising based on reviewer comments. GP and ERU contributed to the design, HPV laboratory analyses and interpretation of findings and revised the article for important intellectual content.

Funding The project described was fully supported by S06-GM08224 from NIH NIGMS MBRS-SCORE Programme, 1G11HD046326 from NICHD/EARDA and 1 SC2 Al090922-01 from MBRS-SCORE, National Institute of Allergy and Infectious Diseases, National Institutes of Health. This study was partially supported by G12RR03051 from NIH/NCRR/RCMI/UPR, NCRR Award Number U54-RR 026139-01A1 \& NIMHD Award Number 8U54-MD 007587-03 5R25CA094186-07 from Training in Computational Genomic Epidemiology of Cancer, National Institute of Cancer and by U54CA96297, U54CA96300 from U54 Partnership for Excellence in Cancer Research, National Cancer Institute. The Centers for Disease Control and Prevention provided support for HPV testing.

Competing interests None.

Ethics approval All study procedures were reviewed and approved by the Institutional Review Board of the University of Puerto Rico Medical Sciences Campus.

Provenance and peer review Not commissioned; externally peer reviewed.

Data sharing statement No additional data are available.

Open Access This is an Open Access article distributed in accordance with the Creative Commons Attribution Non Commercial (CC BY-NC 3.0) license, which permits others to distribute, remix, adapt, build upon this work noncommercially, and license their derivative works on different terms, provided the original work is properly cited and the use is non-commercial. See: http:// creativecommons.org/licenses/by-nc/3.0/

\section{REFERENCES}

1. Carter JJ, Koutsky LA, Hughes JP, et al. Comparison of human papillomavirus types 16,18 , and 6 capsid antibody responses following incident infection. $J$ Infect Dis 2000;181:1911-19.

2. Vaccarella S, Franceschi S, Clifford GM, et al. Seroprevalence of antibodies against human papillomavirus (HPV) types 16 and 18 in four continents: the International Agency for Research on Cancer HPV Prevalence Surveys. Cancer Epidemiol Biomarkers Prev 2010;19:2379-88.

3. Parkin DM, Bray F. The burden of HPV-related cancers. Vaccine 2006;24(Suppl 3):S11-25.

4. Rama CH, Villa LL, Pagliusi S, et al. Seroprevalence of human papillomavirus $6,11,16$ and 18 in young primiparous women in Sao Paulo, Brazil. Int J Gynecol Cancer 2010;20:1405-10. 
5. Chesson H, Blandford J, Gift TL, et al. The estimated direct medical cost of sexually transmitted diseases among American youth, 2000. Perspect Sex Reprod Health 2004;36:11-19.

6. Villa LL. HPV prophylactic vaccination: the first years and what to expect from now. Cancer Lett 2011;305:106-12.

7. Stone KM, Karem KL, Sternberg MR, et al. Seroprevalence of human papillomavirus type 16 infection in the United States. J Infect Dis 2002;186:1396-402.

8. Hagensee ME, Koutsky LA, Lee SK, et al. Detection of cervical antibodies to human papillomavirus type 16 (HPV-16) capsid antigens in relation to detection of HPV-16 DNA and cervical lesions. J Infect Dis 2000;181:1234-9.

9. Lehtinen M, Pawlita M, Zumbach K, et al. Evaluation of antibody response to human papillomavirus early proteins in women in whom cervical cancer developed 1 to 20 years later. Am J Obstet Gynecol 2003;188:49-55.

10. Lu B, Viscidi RP, Lee JH, et al. Human papillomavirus (HPV) 6, 11, 16 , and 18 seroprevalence is associated with sexual practice and age results from the multinational HPV Infection in Men Study (HIM Study). Cancer Epidemiol Biomarkers Prev 2011;20:990-1002.

11. Scherpenisse M, Mollers M, Schepp RM, et al. Seroprevalence of seven high-risk HPV types in the Netherlands. Vaccine 2012;30:6686-93.

12. Pérez CM, Marrero E, Meléndez $\mathrm{M}$, et al. Seroepidemiology of viral hepatitis, HIV and herpes simplex type 2 in the household population aged 21-64 years in Puerto Rico. BMC Infect Dis 2010;10:76.

13. Karem KL, Poon AC, Bierl C, et al. Optimization of human papillomavirus-specific enzyme-linked immunosorbent assay. Clin Diagn Lab Immunol 2002;9:577-82.

14. Human papillomavirus laboratory manual [Internet]. 1st edn. Geneva (CH): WHO, 2009 [cited Jun 14 2013]. http://whqlibdoc.who.int/hq/ 2010/WHO_IVB_10.12_eng.pdf

15. Opalka D, Lachman CE, MacMullen SA, et al. Simultaneous quantitation of antibodies to neutralizing epitopes on virus-like particles for human papillomavirus types $6,11,16$, and 18 by a multiplexed luminex assay. Clin Diagn Lab Immunol 2003;10:108-15.
16. Kleinbaum D, Kupper L, Muller K, et al. Applied regression analysis and other multivariable methods. 4th edn. Duxbury Press, 2008.

17. Markowitz LE, Sternberg M, Dunne EF, et al. Seroprevalence of human papillomavirus types 6,11,16 and 18 in the United States: National Health and Nutrition Examination Survey 2003-2004. J Infect Dis 2009;200:1059-67.

18. Desai S, Chapman R, Jit M, et al. Prevalence of human papillomavirus antibodies in males and females in England. Sex Transm Dis 2011:38:622-9.

19. Dunne EF, Nielson CM, Stone KM, et al. Prevalence of HPV infection among men: a systematic review of the literature. $J$ Infect Dis 2006;194:1044-57.

20. Thompson DL, Douglas JM Jr, Foster M, et al. Project RESPECT Study Group. Seroepidemiology of infection with human papillomavirus 16 , in men and women attending sexually transmitted disease clinics in the United States. J Infect Dis 2004;190:1563-74.

21. Bedoya AM, Gaviria AM, Baena A, et al. Age-specific seroprevalence of human papillomavirus $16,18,31$ and 58 in women of a rural town of Colombia. Int $J$ Gynecol Cancer 2012;22:303-10.

22. Porras C, Bennett C, Safaeian M, et al. Determinants of seropositivity among HPV-16/18 DNA positive young women. BMC Infect Dis 2010;10:238.

23. Wiley DJ, Wiesmeier E, Masongsong E, et al. Smokers at higher risk for undetected antibody for oncogenic human papillomavirus type 16 infection. Cancer Epidemiol Biomarkers Prev 2006; 15:915-20.

24. Simen-Kapeu A, Kataja V, Yliskoski M, et al. Smoking impairs human papillomavirus (HPV) type 16 and 18 capsids antibody response following natural HPV infection. Scand J Infect Dis 2008:40:745-51.

25. Romaguera J, Tortolero-Luna G, Marrero E, et al. Factors associated to HPV vaccine awareness in a population-based sample of women in PR. Poster Presentation at: The 28th International Papillomavirus Conference; 2012, November 30-December 6; San Juan, PR. 